\title{
Dairy cow trade-off preference for 2 different lying qualities: Lying surface and lying space
}

\author{
L. Shewbridge Carter, ${ }^{1,2} \odot$ S. M. Rutter, ${ }^{1} \odot$ D. Ball, ${ }^{3} \odot$ J. Gibbons, ${ }^{3} \odot$ and M. J. Haske $I^{2 *} \odot$ \\ ${ }^{1}$ Department of Animal Production, Welfare and Veterinary Science, Harper Adams University, Edgmond, Newport, Shropshire TF10 8NB, \\ United Kingdom \\ ${ }^{2}$ Scotland's Rural College (SRUC) Research, West Mains Road, Edinburgh EH9 3JG, United Kingdom \\ ${ }^{3}$ Agriculture and Horticulture Development Board (AHDB), Stoneleigh, Kenilworth CV8 2TL, United Kingdom
}

\begin{abstract}
Lying down is an important behavior for cows, contributing to their health and welfare. With dairy cows being housed for increasingly longer periods, if not yearround, it is important to ensure that dairy cow lying comfort is not compromised when they are housed. The aim of this study was to assess cow preference for 2 different qualities of lying area that appear to be important to cows - surface type and an open lying space - to better understand how to optimize lying comfort for cows when housed. Twenty-four Holstein dairy cows were used during the study, which took place in Scotland from July to November 2018. The study consisted of 6 experimental periods, each lasting a total of $21 \mathrm{~d}$. Cows were tested 4 at a time and individually housed in their own test pen. Each pen had 3 lying surfaces: sand, mattress, and straw $(2.4 \mathrm{~m} \times 2.4 \mathrm{~m}$ each $)$ with a freestall in the middle of each, which could be removed. Cows were given access to one surface at a time (training period) with a freestall for $2 \mathrm{~d}$, and then given a choice of all 3 surfaces for $2 \mathrm{~d}$. When given the choice with freestalls in position, cows spent, on average, the largest amount of their lying time on straw $(46.6 \pm 7.8 \%)$ followed by mattress $(44.3 \pm 12.4 \%)$. Freestalls were then removed and the training and choice phase was repeated on the following day, with cows, on average, spending the most time lying on straw $(64.4 \pm 7.2 \%)$. Finally, a freestall was refitted onto each cow's most preferred surface and the cows were given a choice between lying on their most preferred surface with a freestall $(\mathrm{P} 1+$ freestall $)$ or on their second or third preferred surface without a freestall (P2 + open and P3 + open, respectively) for $3 \mathrm{~d}$. During this final trade-off stage, of the 19 cows for which data were available, 14 cows chose to give up the opportunity to lie down on their most preferred surface to have more space on P2 + open and P $3+$ open, 3
\end{abstract}

Received April 24, 2020.

Accepted August 7, 2020.

*Corresponding author: marie.haskell@sruc.ac.uk cows chose to lie down on $\mathrm{P} 1+$ freestall, and 2 cows made no clear choice. Overall, cows spent the largest amount of their total lying time on their second most preferred surface as an open lying space $(65.7 \pm 6.9 \%)$ compared with their preferred surface with a freestall $(20.5 \pm 5.9 \%)$ and their third preferred surface as an open lying space $(13.8 \pm 3.7 \%)$. The results indicate that when lying down, these dairy cows value an open lying space more than the lying surface.

Key words: preference, behavior, welfare, housing

\section{INTRODUCTION}

Rest is important to animals, to conserve energy and allow for metabolic recoveries (Fraser, 1983), with cows mostly resting while lying down rather than standing (Kilgour, 2012). Dairy cows deprived of lying down have been shown to prioritize the behavior over other deprived behaviors, such as feeding and socializing, and appear to work toward a set amount of time to lie down per day (Metz, 1985; Munksgaard et al., 2005). Cows deprived of lying are more likely to shift their weight and foot stomp, indicating discomfort (Cooper et al., 2007) and, when deprived for $4 \mathrm{~h}$, are quicker to push a weighted pneumatic gate to gain access to a deep-bedded lying area, indicating a motivation for a comfortable lying area (Tucker et al., 2018).

With the majority of dairy cows experiencing indoor housing at some point throughout their lives (99\% of British cows and $>99 \%$ of cows in the United States are housed for some period within each year; March et al., 2014; USDA, 2016) and year-round housing growing in popularity (Haskell et al., 2006; van den Pol-van Dasselaar et al., 2008), it is more relevant than ever to ensure housed environments are meeting the behavioral and welfare needs of cows. When cows are housed, freestall housing is most common, with the freestall design developing from original tiestall designs (Margerison, 2011). Knowing the importance of lying down for cows, much research has been done on cow lying preference for various freestall modifications, 
such as stall size (width and length: Tucker et al., 2004; neck rail placement: Tucker et al., 2005), surface type (Manninen et al., 2002; Tucker et al., 2003), bedding type (Norring et al., 2010), and alternative stall design (Abade et al., 2015). Cow preference for the freestall has also been tested against open lying spaces, such as pasture (Legrand et al., 2009; Charlton et al., 2011, 2013; Motupalli et al., 2014), indoor open pack areas (Fregonesi et al., 2009), and outdoor open pack areas (Smid et al., 2019); however, these studies have confounded the factors of surface type, size of total lying area, and indoor versus outdoor conditions. In general, cows prefer to lie on a soft surface, a stall with larger dimensions or an open lying surface; however, it is unclear which of these is lying qualities is most important to cows and where the focus should be when improving lying comfort when cows are housed.

In the current study, 2 different lying qualities that appear to be important to cows were selected as the focus: surface type and open space. The aim was to investigate the importance a cow puts on these 2 different aspects of a lying area. This was done by establishing their preference between 3 different lying surfaces: deep-bedded sand, rubber mattress, and deep-bedded straw, both with and without a freestall on them. Once surface preference was established, the cows were given a choice to lie down on their most preferred surface with a freestall or on lesser preferred surfaces with no freestall. This presented the cow with a trade-off between surface type and open space when lying down to establish whether lying space or surface was more important to them. Based on these previous studies, we predicted that during the trade-off, cows would trade lying on their preferred surface with a freestall and lie down for longer periods on either of the 2 less preferred surfaces without freestalls, indicating a preference for an open lying area over a preferred lying surface.

\section{MATERIALS AND METHODS}

Ethical approval for this study was given by Scotland's Rural College (SRUC) Animal Ethics Committee (ED AE 12-2018), and the work was conducted under the authority of the UK Animal (Scientific Procedures) Act 1986 (Home Office, 1986).

\section{Animals and Management}

The study was carried out at Crichton Farm, SRUC Dumfries, Scotland, United Kingdom, in an open-sided barn. Twenty-four pregnant Holstein dairy cows (3 primiparous and 21 multiparous) with an average ( \pm SEM) lactation number of $2.75( \pm 0.3)$ in mid to late lactation ( $271 \pm 14.8$ DIM; range 142 to 412 DIM), with a milk yield between 12.2 and $29.4 \mathrm{~kg} / \mathrm{d}$ (mean $20.8 \pm$ $0.79 \mathrm{~kg} / \mathrm{d})$ and that weighed on average $728 \mathrm{~kg}( \pm 11.7$ $\mathrm{kg}$; range $643-847 \mathrm{~kg}$ ) were selected for the study. Cows were selected based on milk yield $<35 \mathrm{~kg}$, with a BCS between 2.75 and 3.5 (mean $3 \pm 0.03$ ), as described by the Penn State method (Ferguson et al., 1994), and a lameness score $(\mathbf{L S})$ no greater than 2 (mean $2 \pm 0.1$; 2 = imperfect locomotion but ability to move freely not diminished; Flower and Weary, 2006). Body condition and LS were assessed by the same person (LSC) while cows walked across a concrete floor after their $\sim 1500 \mathrm{~h}$ milking 1 wk before cows came on trial.

The cows were allocated to 1 of 6 experimental periods according to their stage of lactation $(\mathrm{n}=4 \times 6)$, which were carried out from July 10 to November 12, 2018 (study period 1: July 10 to July 30; study period 2: July 31 to August 20; study period 3: August 21 to September 10; study period 4: September 11 to October 1 ; study period 5: October 2 to October 22; October 23 to November 12). Each experimental period lasted for a total of $21 \mathrm{~d}$ : $1 \mathrm{~d}$ for set-up, $6 \mathrm{~d}$ for training, a 2-d choice period, followed by $1 \mathrm{~d}$ to move and reset equipment, followed by another 6 -d training and 2-d choice period, finishing with a 3 -d trade-off choice period (Figure 1).

Cows were individually penned while participating in the study to ensure that during the free-choice periods, their choice was not influenced by the presence of other animals that might potentially be competing for the same resource or otherwise influence their choice of where to lie down. All cows were assigned to one pen for the duration of the study and had visual and tactile contact with a test cow in the adjacent pen.

Before the study, the cows in this herd had been housed indoors in a freestall barn on mattresses, milked 3 times a day $(0700,1500$, and $2200 \mathrm{~h}$ ), with experience of straw pens during the precalving period, and had pasture access during the day from July to October or November, depending on weather conditions and harvesting schedules. This ensured that they had experience of lying on mattress-bedded freestalls and in straw. One week before the start of a new experimental period, cows due to go on trial were housed together in a pen with a deep-bedded sand area for lying, to allow them to experience sand as a lying surface. During this week, the cows were also brought down from 3 to 2 milkings a day, to better emulate common practice on British farms.

\section{Performance and Lameness}

Throughout the study, milk yield was recorded automatically at each milking for individual cows and was used to calculate average yield per cow for the duration of their time on the study. 
Body condition and LS were recorded when cows were on trial on d 1, 10 and 20 while cows were returning to trial pens after the morning milk, at approximately $0700 \mathrm{~h}$. The average BCS and LS of each cow was calculated as the mean of these 3 scores.

After each milking, cows were automatically weighed when leaving the parlor. Data recorded after both morning and evening milkings were used to calculate the average weight for each cow for their duration on the study.

\section{Experimental Design and Housing}

Twice a day, at around 0600 and $1830 \mathrm{~h}$, cows were collected and taken to the milking parlor (14:14 herringbone parlor; DeLaval, Tumba, Sweden) and milked after the main herd in the morning and before the main herd in the evening, to allow for a near $12 \mathrm{~h}: 12 \mathrm{~h}$ split. No concentrates were fed during milking. Following the morning $(\sim 0700 \mathrm{~h})$ and evening $(\sim 1900 \mathrm{~h})$ milkings, the cows were returned to their pens and manually separated into their own pens. Cows experienced the lying treatments within the pens for approximately 11 $\mathrm{h}$ between morning and evening milking and $11.5 \mathrm{~h}$ between evening and morning milking. Eight security cameras (Viewlog, GeoVision Inc., Taiwan), 2 per pen, were set up to continuously record cow behavior within the pens, and each cow wore an accelerometer (IceTag; Ice Robotics, Edinburgh, UK) on their hind leg to automatically record lying behavior. Cows first entered the pens after a morning milking and, from then on, each experimental "day" began when the cows were put into their pens after the morning milking and ended with the start of morning milking the following day.
Pen Housing Layout. A $365-\mathrm{m}^{2}$ area of an opensided barn, separate from the barn where the main herd was housed, was divided into 4 pens to house each cow individually $(6.0 \mathrm{~m} \times 15.2 \mathrm{~m}$; Figure 2$)$. Each pen had 3 different lying surfaces: $20 \mathrm{~cm}$ of sand (SA), rubber mattress bedded with sawdust (M; Pasture Mat; Wilson Agri, Coleraine, UK); and $20 \mathrm{~cm}$ of wheat straw (ST) contained in wooden boxes, $2.4 \times 2.4 \times 0.2 \mathrm{~m}$, with each able to have a freestall and rounded plastic brisket board fitted or removed, depending on the experimental stage (Figure 3). Each surface was separated from the next one by $2.0 \mathrm{~m}$ and was $1.8 \mathrm{~m}$ from the edge of the pen. This allowed a cow access from any side when freestalls were removed and discouraged a cow from using multiple surfaces at one time (Figure 2).

A Latin square design was used to allocate the surfaces to the 3 locations in each pen, such that each surface occurred in each location at least once and that no cow had the same layout of surfaces as her neighbor (Figure 2). This was to consider the order effect of the training stages, whereby cows had access to one lying surface at a time and were encouraged to lie down on each so that they experienced all of the lying surfaces.

After the second and fourth experimental periods, the location of surfaces within pens were moved to account for location effect within the barn, as per another Latin square design (Figure 4).

Pens provided individual ad libitum access to feed and water. An ad libitum TMR was provided daily at approximately $1000 \mathrm{~h}$, with feed refusals being removed every day before fresh feed was provided. Water buckets were emptied and refilled every other day. Pens were cleaned out once a day at approximately $0900 \mathrm{~h}$, with lying surfaces being tended to at this time; that is,

\section{Stage 1: Freestalls \\ Freestalls On}

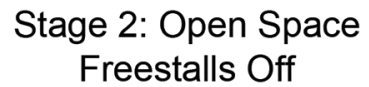

Stage 3: Trade-Off

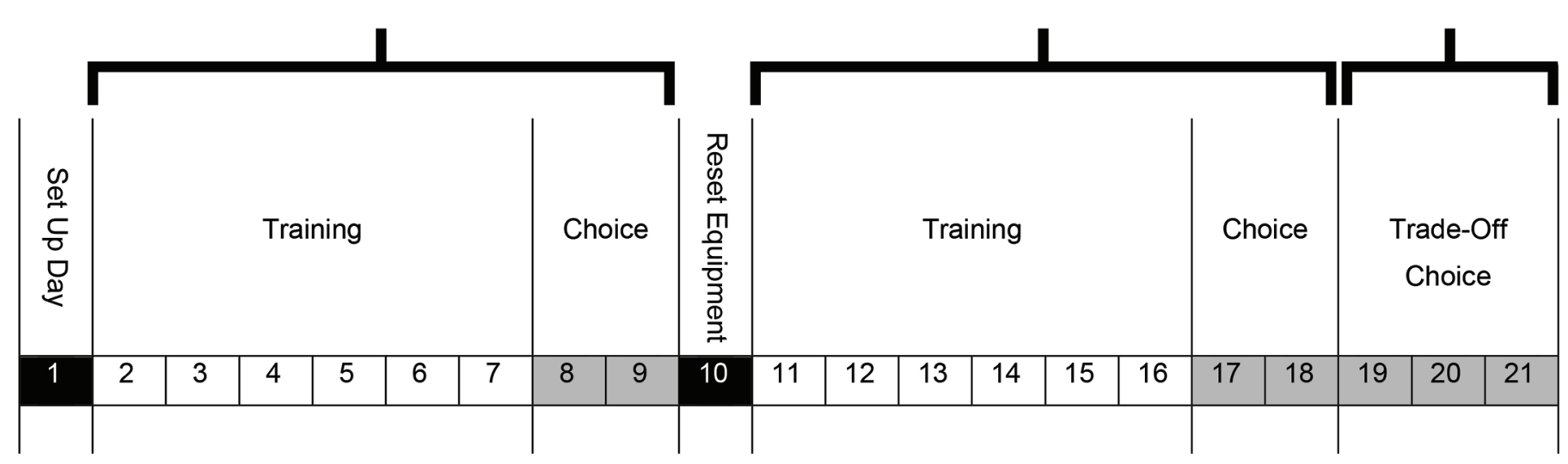

Figure 1. Representation of the 21-d experimental period, which was repeated 6 times using 4 cows. Days shaded in black represent equipment set-up days when cows were not present in the pens. Days shaded in gray represent days when cows had a choice of all lying surfaces. 

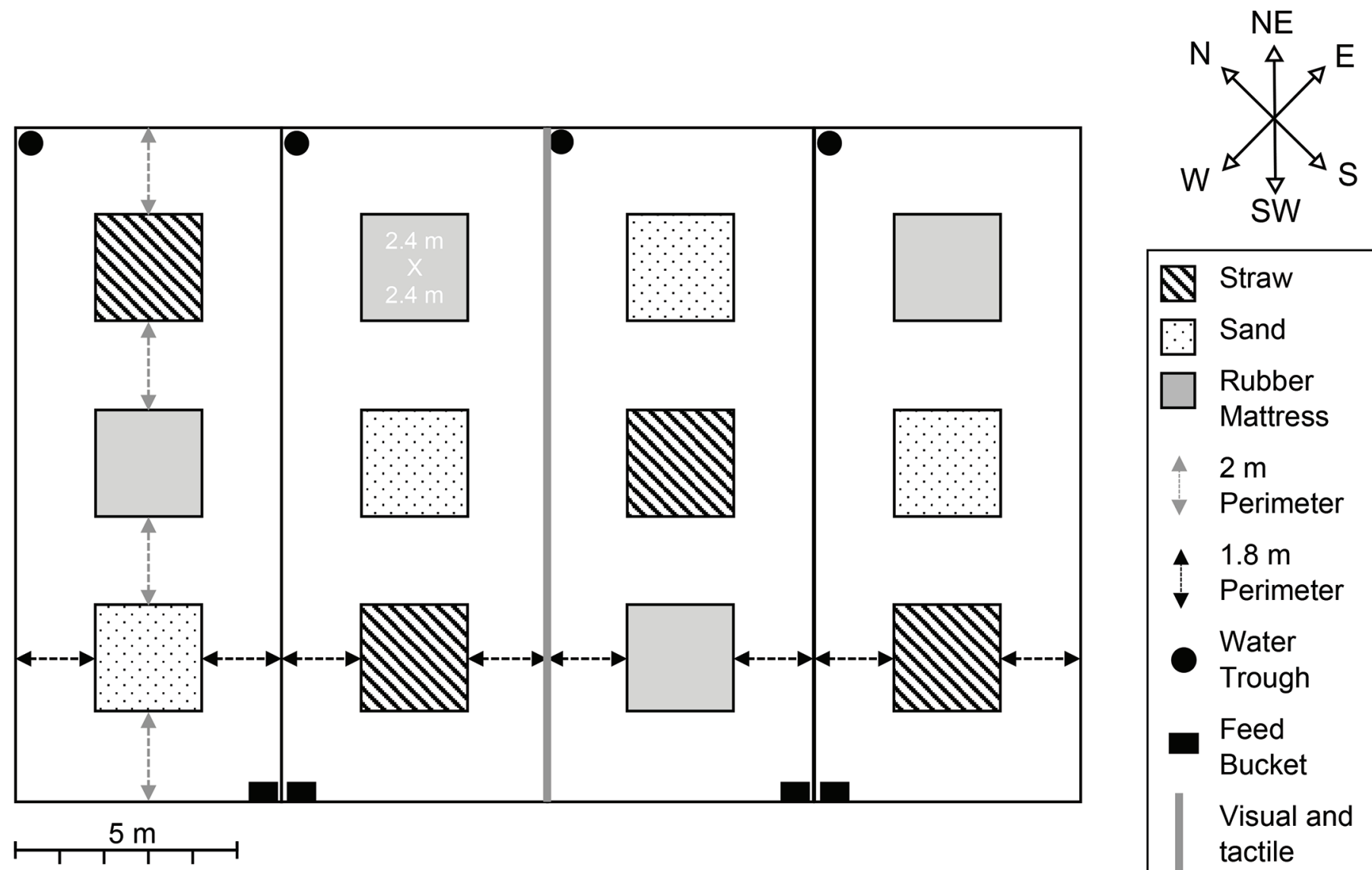

\begin{tabular}{|ll|}
\hline $\mathbf{W}$ & Straw \\
$\because$ & Sand \\
\hline & Rubber \\
Mattress & $2 \mathrm{~m}$ \\
& Perimeter \\
& $1.8 \mathrm{~m}$ \\
Perimeter & Water \\
Trough \\
Feed \\
Bucket \\
Visual and \\
tactile \\
partition
\end{tabular}

Figure 2. Plan of barn divided into 4 pens with 3 lying surfaces - straw, sand, and rubber mattress - in each used for the experiment.

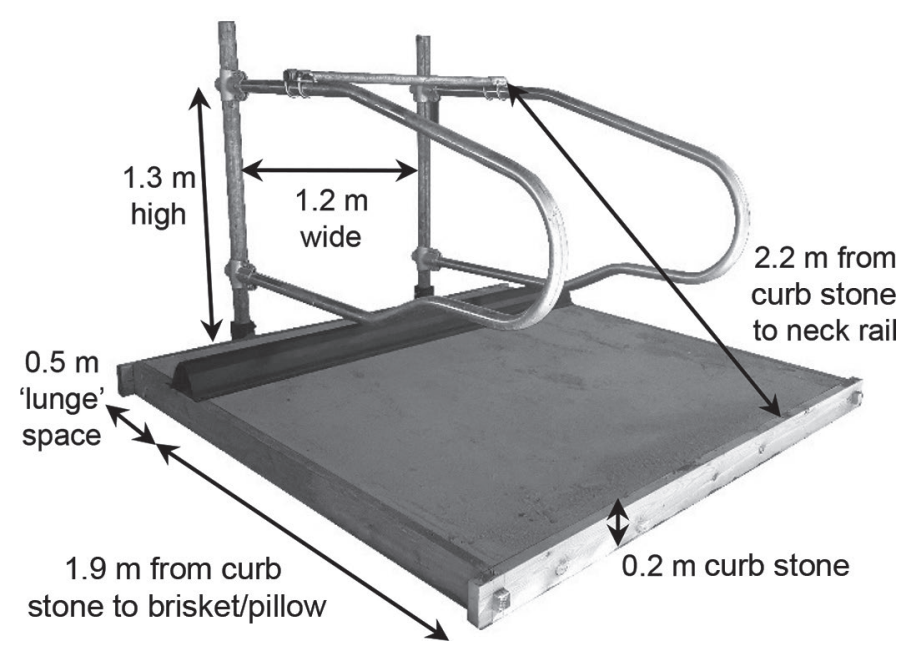

Figure 3. Photograph of freestall design over deep-bedded sand surface with freestall dimensions. sand was flattened, rubber mattresses were re-covered with sawdust, and fresh straw was topped up. Following the evening milking, lying surfaces were cleaned where necessary.

Experimental Design. Preference studies used as a measure of welfare run the risk of either measuring a preference for the "lesser of two evils" or indeed choosing the better of 2 good options. An animal forced to take the less preferred option does not necessarily experience good animal welfare (Duncan, 1992). By giving a choice of more than 2 options, the range of choice is widened to help overcome these risks when interpreting the results. A preference study with just 2 choices requires preference to be defined as $>50 \%$ use of one of the options, with random choice being 50:50. Throughout the current study, for one lying option to be preferred out of the 3 possible options, the percentage of total lying time for the most preferred must at least be $>33.3 \%$; however, we considered that cows showed a strong preference when the percentage of lying time on any one surface was $>60 \%$, with the 
maximum combined total for the remaining 2 surfaces being $40 \%$ of lying time.

Each experimental period comprised 3 stages, as follows: stage $1=$ freestalls, stage $2=$ open space, and stage $3=$ trade-off, with each lasting a total of $20 \mathrm{~d}$, not including the initial set-up day (refer to Figure 1). Below is a description of the 3 stages for one cow.

Stage 1: Freestalls. Freestalls were fitted to each lying surface in an orientation that allowed companion cows to face one another when lying down. The introduction of the freestall on the lying surfaces was to control lying posture and orientation, as a regular freestall would. A training period of $6 \mathrm{~d}$ consisted of the cow having access to one surface at a time for 2 consecutive days, with the other 2 surfaces blocked off using sheep pen hurdles. Training began with cows having access

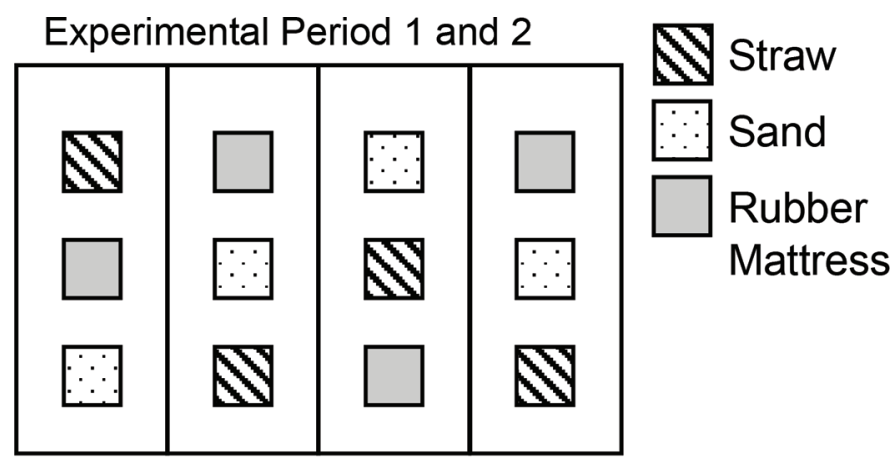

Experimental Period 3 and 4

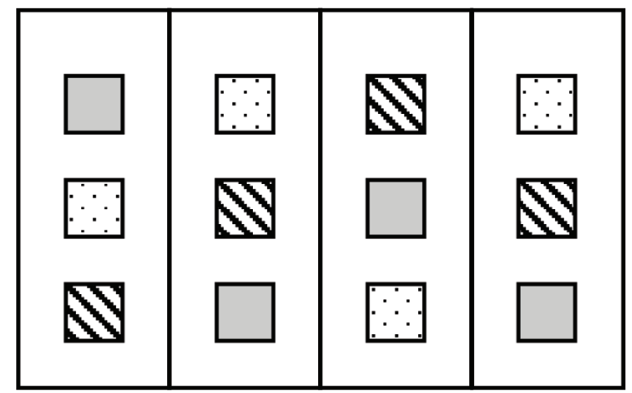

Experimental Period 5 and 6

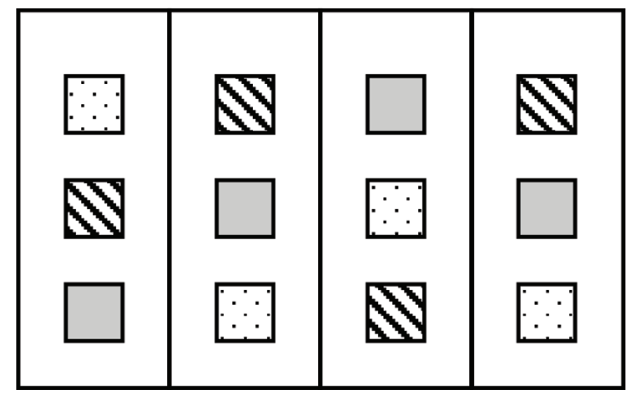

Figure 4. Plan of barn surface layout demonstrating the Latin square design for changing surface location after every 2 experimental periods. to the surface in their pen on the northeast side of the barn, followed by the middle surface, and finally having access to the surfaces on the southwest side of the barn. This allowed the cow to experience each of the 3 lying surfaces with a freestall. A training protocol was in place for cows that did not understand that they could lie down in the freestall. This consisted of training the cow to follow a bucket of concentrated pellets into the freestall so that all 4 hooves were on the lying surface. Cows were rewarded here with pellets left in the lunge area, the bucket removed, and the following behaviors observed. For cows that did not lie down within the first 10 min or left the lying surface, this was repeated multiple times. All cows did lie down on each lying surface during this training period.

After the 6-d training period, all hurdles were removed and the cow was given free choice between all 3 lying surfaces with freestalls on for $2 \mathrm{~d}$.

Stage 2: Open Space. One day was taken between stage 1 and stage 2 to remove all freestalls and brisket boards from the pens, with the cows kept on freestalls in the main herd barn overnight.

When the cow returned to the pen the following day, with all freestall dividers and brisket boards removed, a training period equivalent to that in stage 1 began, with the cow having access to one surface at a time, in the same order as previously, for 2 consecutive days, with the other 2 surfaces blocked off with sheep pen hurdles. This allowed the cow to experience each of the lying surfaces without a freestall and allowed the cow an opportunity to express a range of different lying postures and orientations that might be expressed in an open lying space. After the 6-d training period, all sheep pen hurdles were removed and the cow was given free choice between all 3 lying surfaces for $2 \mathrm{~d}$.

The video footage of the middle $24 \mathrm{~h}$ of this choice period was analyzed to determine the cow's most preferred lying surface (largest percentage of lying time, with a minimum threshold of $60 \%$ ) to determine where to refit the freestall in stage 3 . This was because of the time constraint between the end of stage 2 and the need to refit a freestall before the beginning of stage 3 . The full $48 \mathrm{~h}$ of video footage was used for in the final analysis of stage 2 . It also showed that for most cows (but see below), the preference exhibited in the middle $24 \mathrm{~h}$ represented the choice over the whole period.

After viewing the middle $24 \mathrm{~h}$ of video footage, 3 cows did not have a preferred lying surface, with no lying surface meeting the minimum threshold of $60 \%$ total lying time; therefore, the full 48 -h period was analyzed for these cows. From this, a preferred lying surface was determined for 2 of the cows $(>60 \%)$ and 1 cow did not meet the minimum threshold of $60 \%$ for one lying surface. The cow for which a preferred surface 
could not be determined was excluded from the statistical analysis for stage 3 .

Stage 3: Trade-Off. In this stage, the cow's most preferred lying surface, as determined in the previous stage, had a freestall and brisket board refitted. The 2 less preferred surfaces were left without a freestall. Hereafter, $\mathrm{P}$ indicates preference, and the numbers 1 to 3 indicate the order of preference from first to third. Thus, the configuration of the most preferred surface is shown as "P1 + freestall," and the open surfaces as "P2 + open" and "P3 + open." The cow then had free choice between these lying options for $3 \mathrm{~d}$, giving her the choice between whether lying surface or space for lying was more important to her.

\section{Measurements}

Behavioral Measures. Time in and out of the pen each day (i.e., at milking) was recorded from the video data to obtain a total time in pen per day for each cow. For each cow during the training periods, when there was no choice for lying location, the IceTag data were analyzed to obtain lying bout start and end time. For choice periods, video data were used to obtain start time, end time, and location of each lying bout for each cow. From this, the proportion of each day spent lying on each of the surfaces was calculated, along with the frequency and duration of each lying bout for training and choice periods.

Weather Conditions. Weather conditions were recorded daily at $1000 \mathrm{~h}$ automatically throughout the study period using a Meteorological Office weather station $\sim 220 \mathrm{~m}$ from the barn. Outdoor dry temperature $\left({ }^{\circ} \mathrm{C}\right)$, rainfall $(\mathrm{mm})$, wind speed (Beaufort scale), and wind direction (on a 32 -point scale with north $=1 / 32$, east $=8$, south $=16$, and west $=24$ ) was recorded.

\section{Statistical Analysis}

Training Stage 1 Freestall On and Stage 2 Freestall Off. For the training period, the time spent lying down on each surface was analyzed as a percentage of total time in the pen for the second day of training on each surface for stage 1 and stage 2 , as all cows had been successfully trained after the first $24 \mathrm{~h}$. A general linear model was used to analyze lying behaviors during training (percentage of time spent lying, lying bout duration, and lying bout frequency). This model was created to test the effect of surface type, stage, order of training, and for a surface type $\times$ stage interaction, blocked by cow ID.

Choice Periods Stages 1, 2, and 3. During the choice period of stage 1 and stage 2, cow preference for surface type was determined by analyzing the percent- age of total time lying on each surface during the $2 \mathrm{~d}$ of choice for each stage, applying a mixed model using the REML algorithm. The fixed-effects model was created to test the effect of surface type, location of surface, and surface type $\times$ location interaction. Surface type $\times$ repetition, surface type $\times$ pen location, and surface type $\times$ cow ID interactions were used as the random model. When analyzing stage 2 , the location of the surface and surface type $\times$ location of surface interaction was dropped from the model when found to be nonsignificant.

The total percentage of time spent lying down was calculated for the training and choice periods of stage 1 and stage 2 . The data were normally distributed and a 2-way ANOVA was used to test for a difference in time spent lying down between stages 1 versus 2 and training periods versus choice periods, blocked by cow ID, and to determine whether there was an interaction between time spent lying down during stage 1 and $2 \times$ training and choice periods. Paired $t$-tests were used to determine whether there was a difference between (a) lying bout frequencies, and (b) lying bout durations between the choice periods of stage 1 and stage 2 .

For stage 3, lying time (in minutes) was analyzed using a series of Wilcoxon matched-pair sign ranks test, paired for each cow, for (a) P1 + freestall against P2 + open, and (b) P1 + freestall against P3 + open, because the data were not normally distributed, even following transformation. Six cows had no preference between P2 and P3 and either one of surfaces could have been preferred in principle. All possible combinations were considered and the Wilcoxon test was applied 64 times $\left(2^{6}=64\right)$ to each possible combination to test for (a) and (b), with the mean values of these 2 series compiled.

Five cows in total were not included in the analysis for stage 3 ; of these 5 , data from 4 cows were lost due to the failure of video recording equipment. The fifth cow did not make a clear choice $(>60 \%)$ for one surface during stage 2 (percentage of lying time on each surface during $48 \mathrm{~h}$ of stage 2 for cow 5 as per Figure 5: SA: 0\%; ST: $54.2 \%$; M: $45.8 \%$ ). These 5 cows were included in the analysis for stage 1 and stage 2 , but not stage 3 .

To investigate whether cows that had a very high percentage of total lying time for one surface during stage $2(>80 \% ; \mathrm{n}=11)$ showed a similarly high percentage for one lying option in stage 3 , we performed a Spearman rank test on the lying option that had the largest percentage of total lying time for these 11 cows for stage 2 and stage 3.

Weather and Performance Factors. Weather factors and surface choice during choice periods for stages 1,2 , and 3 were averaged per repetition, and linear regressions, corrected using Bonferroni corrections, 

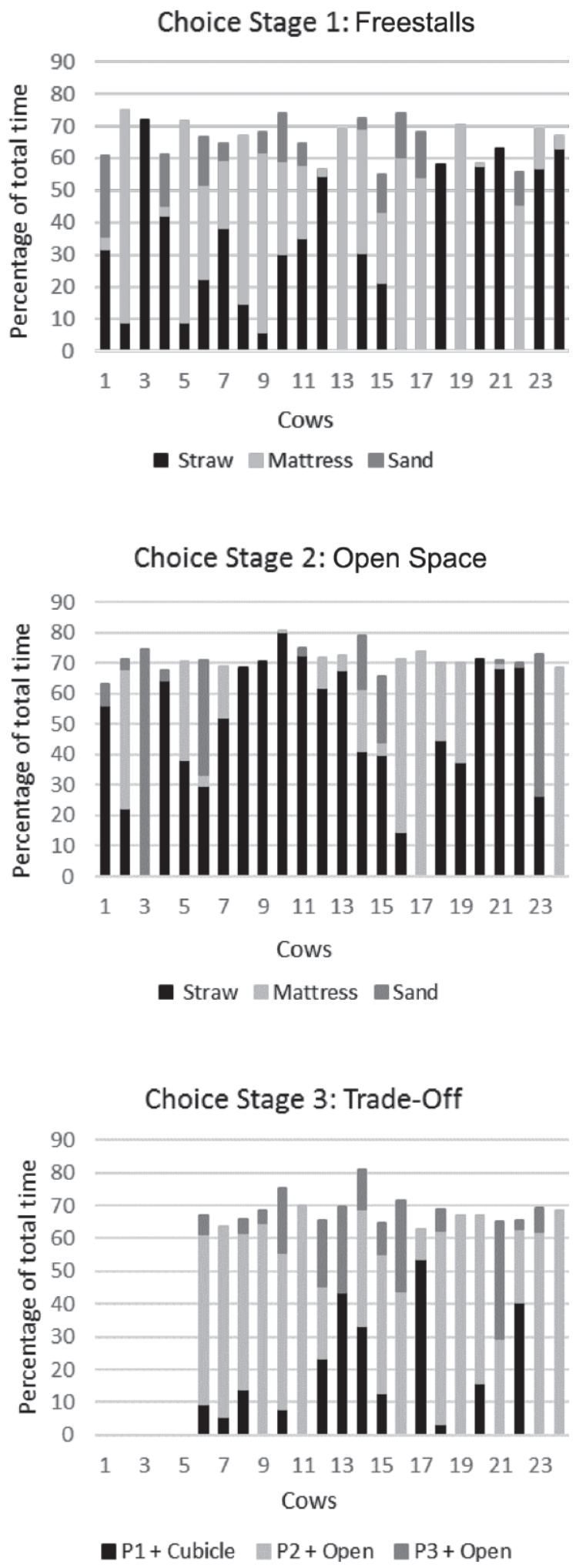

Figure 5. Percentage of total time spent lying on each surface during the choice periods of stage 1 (freestalls; $\mathrm{n}=24$ ), stage 2 (open space; $\mathrm{n}=24$ ), and stage 3 (trade-off; $\mathrm{n}=19$ ) for each individual cow. For stage $3, \mathrm{P} 1+$ freestall $=$ most preferred lying surface with a freestall; P2 + open $=$ second preferred lying surface with no freestall; P3 + open $=$ third preferred lying surface with no freestall. used to assess the effect of weather on choice. These weather data are summarized in Table 1. Multiple regressions, corrected using Bonferroni corrections, were used to test for an effect of cow performance factors on surface choice during choice periods for stage 1,2 and 3. These factors were BCS, LS, DIM, days in calf, lactation number, weight, and yield.

All data were analyzed using GenStat (18th ed., Lawes Agricultural Trust, Rothamsted, UK).

\section{RESULTS}

\section{Training Stage 1 Freestall On and Stage 2 Freestall Off}

The average time spent lying (h), percentage of total time spent lying (\%), average lying bout duration (min), and average lying bout frequency for the second day of training for stage 1 and stage 2 are presented in Table 2.

There was no interaction between surface type $x$ stage and no effect of order on percentage of time spent lying down, lying bout duration, or lying bout frequency during the training periods; these were therefore dropped from the models.

Overall, during the training periods, cows spent 1.1 $\mathrm{h}$ longer lying down during stage 2 , without freestalls [Wald statistic $(\boldsymbol{W})=5.343 ; P=0.022 ; \mathrm{df}=1 ; 67.1 \pm$ $0.9 \%$ ] than during stage 1 , with freestalls $(63.6 \pm 1.2 \%)$. Surface type had no effect on percentage of time spent lying ( $W=0.067 ; P=0.967 ; \mathrm{df}=2$ ). Surface type had an effect on lying bout duration and lying bout frequency, with cows lying for longer but in fewer bouts on SA (lying bout duration: $W=12.975 ; P=0.002$; df $=2$; ST: $83 \pm 3$ min; M: $91 \pm 3.3$ min; SA: $100 \pm 3.9$ min; lying bout frequency: $W=9.573 ; P=0.01$; df $=$ 2 ; ST: $10.7 \pm 0.4$; M: $10 \pm 0.33$; SA: $9.1 \pm 0.32$ ). There was no difference between stage 1 and stage 2 on either lying bout duration $(W=1.593 ; P=0.209 ; \mathrm{df}=1)$ or frequency $(W=0.335, P=0.564 ; \mathrm{df}=1)$.

\section{Choice Periods Stages 1, 2, and 3}

The average time spent lying $(\mathrm{h})$ per day, percentage of total time spent lying (\%), and percentage of total lying time (\%) for stage 1, stage 2 and stage 3 , averaged per cow, are presented in Table 3. The percentage of total time spent lying on each surface during the choice periods of stage 1 , stage 2 , and stage 3 are presented in Figure 5 for each individual cow.

During the 48-h choice period for stage 1 , an interaction was found between surface type and surface location for ST and $\mathrm{M}[W=11.93 ; P=0.03$; denominator degrees of freedom $(\mathbf{d d f})=42]$. Cows lay down longest 
Table 1. Summary of weather data during the 3 -d choice periods for stage 1 (freestalls), stage 2 (open space), and stage 3 (trade-off)

\begin{tabular}{|c|c|c|c|c|c|c|}
\hline Variable & \multicolumn{2}{|c|}{ Stage 1} & \multicolumn{2}{|c|}{ Stage 2} & \multicolumn{2}{|c|}{ Stage 3} \\
\hline Temperature $\left({ }^{\circ} \mathrm{C}\right)$ & $12.9 \pm 1.78$ & $4.6-16.6$ & $13.6 \pm 1.64$ & $8-18.9$ & $12.9 \pm 1.3$ & $9.1-16.2$ \\
\hline Wind speed (Beaufort scale) & $1.6 \pm 1.5$ & $1-5.5$ & $3.2 \pm 0.6$ & $1.5-5.5$ & $3.1 \pm 0.3$ & $2.3-4$ \\
\hline Wind direction (32-point scale) & $24.3 \pm 1.9$ & $22.5-32$ & $20.8 \pm 2$ & $14-27$ & $24.3 \pm 1.8$ & $18.3-27.3$ \\
\hline
\end{tabular}

on $\mathrm{M}$ when in the middle of the pen (northeast: 18.6 $\pm 9.5 \%$; middle: $46.1 \pm 6.8 \%$; southwest: $25.8 \pm 8.9 \%$ ) but longest on ST when in the southwest of the pen (northeast: $17.6 \pm 7.2$; middle: $31 \pm 8 \%$; southwest: 41 $\pm 9.1 \%)$.

Overall, cows lay down for $>5 \mathrm{~h}$ longer on ST and M than on SA $(W=11.45 ; P=0.02$; ddf $=11$; SA: 5.8 $\pm 1.5 \%$; ST: $29.9 \pm 4.9 \%$; M: $30.2 \pm 5.3 \%$ ). This was due to some cows having a strong preference for ST (9 cows $>60 \%$ of lying time) and some for M (9 cows $>60 \%$ of lying time), rather than cows splitting their time between ST and M (Figure 5).

During the 48-h choice period in stage 2, no interaction was found between surface type and surface location, and the interaction was dropped from the model. A difference was found between the percentage of time spent lying on the different surface types ( $W=66.82$; $P=0.027 ; \mathrm{ddf}=2.1$ ) with cows spending more time lying down on ST than on M or SA (SA: $9 \pm 3.8 \%$; ST: $45.8 \pm 5.1 \%$; M: $16.5 \pm 4.7 \%$ ). Cows were found to spend a greater percentage of their time lying down during stage 2 than stage $1(F=22.16 ; P<0.001$; df $=1 ; 71.3 \pm 0.8 \%$ vs. $65.9 \pm 1.3 \%)$. Percentage of time spent lying in the training periods was found to be lower than during the choice periods for stages 1 and $2(F=13.43 ; P<0.001 ; \mathrm{df}=1 ; 64.9 \pm 1.1 \%$ vs. 68.6 $\pm 0.8 \%)$, a difference of $<1 \mathrm{~h}$. We found no interaction between stage 1 and $2 \times$ training and choice periods $(F=0.37 ; P=0.543 ; \mathrm{df}=1)$. There was no difference in lying bout frequency between the choice periods of stage 1 and stage $2(t=-1.1 ; P=0.284 ; \mathrm{df}=23 ; 20$ \pm 0.7 and $20.6 \pm 0.6$, respectively) and no difference in lying bout duration between the choice periods of stage 1 and stage $2(t=-1.42 ; P=0.168 ; \mathrm{df}=23 ; 90 \pm 3.1$ and $94 \pm 2.5 \mathrm{~min})$.

For the trade-off choice period of stage 3 , the 64 combinations of Wilcoxon tests were averaged to obtain a mean $P$-value. The results showed that cows lay down on average for $>6 \mathrm{~h}$ longer on $\mathrm{P} 2+$ open than $\mathrm{P} 1+$ freestall $(W=35.25 ; P=0.023 ; \mathrm{P} 1: 13.9$ $\pm 3.9 \%$; P2: $44.8 \pm 4.7 \%$ ), expressing a strong preference to lie down on P2 + open (65.7\% of total lying time) compared with lying on P1 + freestall (20.5\%). There was no difference in lying times between P1 + freestall and P3 + open $(W=64.44 ; P=0.730 ;$ P3: $9.5 \pm 2.5 \%)$.

For cows that expressed a high percentage of lying time on one surface $(>80 \%)$ during stage $2(n=11)$, no correlation was found for the largest percentage of total lying time for one lying option between stage 2 and stage 3 (Spearman's rho $=0.471 ; P=0.144$ ). These cows had an average lying time on one surface of $97.3 \%$ during stage 2 , which decreased to an average of $73.3 \%$ during stage 3 .

\section{Weather and Performance Factors}

Weather factors had no effect on cow surface choice for stages 1,2 , and 3 . No cow performance effects on cow surface choice were found for stage 1 and stage 2 .

Table 2. Summary, averaged for all cows, of lying time, percentage of total time spent lying, and lying bout duration and frequency for the second day of training of stage 1 (freestalls; $n=24$ ) and stage 2 (open space; $n=24$ ), when cows only had access to one lying surface at a time, for each lying surface and average for stage 1 and stage $2( \pm \mathrm{SEM})$

\begin{tabular}{|c|c|c|c|c|}
\hline Variable & Sand & Straw & Mattress & Average \\
\hline \multicolumn{5}{|l|}{ Stage 1} \\
\hline Lying time $(\mathrm{h})$ & $13.9 \pm 0.47$ & $13.14 \pm 0.78$ & $14.55 \pm 0.42$ & $13.86 \pm 0.34$ \\
\hline$\%$ of total time spent lying & $62.5 \pm 2.1$ & $60.3 \pm 3.6$ & $65.7 \pm 1.8$ & $62.8 \pm 1.7$ \\
\hline Lying bout frequency (no.) & $8.9 \pm 0.5$ & $10.6 \pm 0.7$ & $10 \pm 0.3$ & $9.8 \pm 0.3$ \\
\hline \multicolumn{5}{|l|}{ Stage 2} \\
\hline Lying time $(\mathrm{h})$ & $14.93 \pm 0.44$ & $15.48 \pm 0.21$ & $14.46 \pm 0.4$ & $14.96 \pm 0.21$ \\
\hline
\end{tabular}


Table 3. Summary, averaged for all cows, of average lying time per day (h), average percentage of total time spent lying per day (\%), and average percentage of total lying time per day on each lying option and an average daily total for all lying options combined (daily average) for the choice periods of stage 1 (freestalls; $\mathrm{n}=24)$, stage 2 (open space; $\mathrm{n}=24)$, and stage 3 (trade-off; $\mathrm{n}=19)( \pm \mathrm{SEM})$

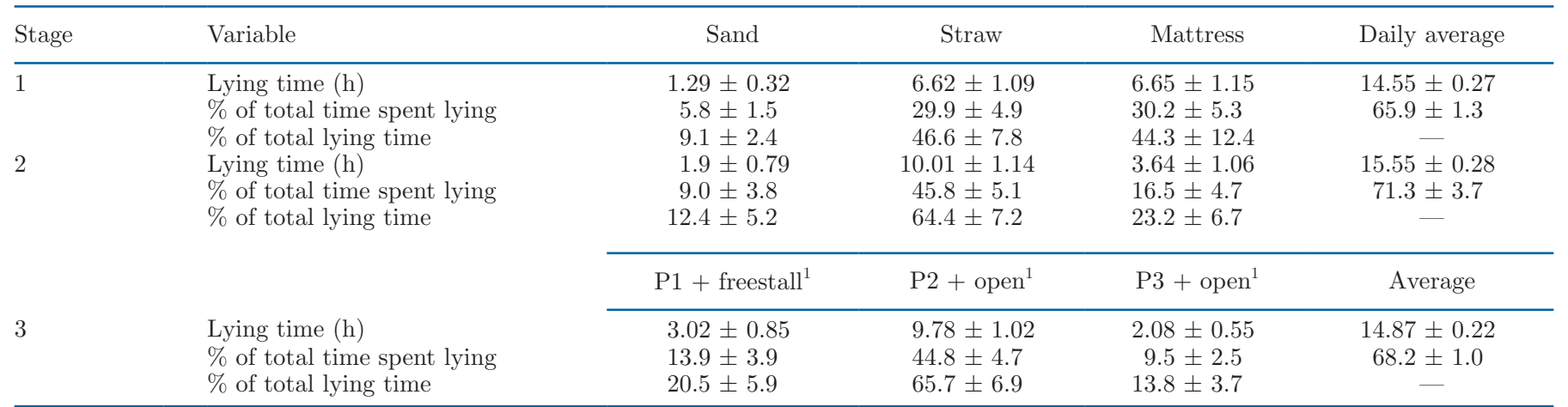

${ }^{1} \mathrm{P} 1+$ freestall represents the cow's first surface preference from stage 2 with the addition of a freestall structure, P2 + open is the second most preferred surface without a freestall, and P3 + open is the third most preferred surface without a freestall.

An interaction between number of lactations and cow choice during stage 3 was the only cow performance effect at this stage $(P=0.015 ; 3 \pm 0.3)$. Cows with fewer lactations $(\leq 2.9)$ spent a larger percentage of time lying on $\mathrm{P} 2+$ open than higher lactation cows $(57.8 \pm 3.2 \%$ vs. $33.2 \pm 6.6 \%$, for below-average and above-average lactation number, respectively) but spent a shorter percentage of time on $\mathrm{P} 1+$ freestall $(4.9 \pm 2.2 \%$ vs. $19.8 \pm$ $6.2 \%)$ and P3 + open ( $5 \pm 3 \%$ vs. $13.6 \pm 3.6 \%)$.

\section{DISCUSSION}

The objective was to establish what aspect of a lying area was more important to a cow, the surface type or an open space, using a preference trade-off. The majority of cows in this study had a strong preference to lie down in an open space on a surface they had not shown a strong preference for previously, suggesting that they were prepared to give up their preferred surface to have an open space to lie in. There was no difference in lying time found between P1 + freestall and P3 + open, suggesting that lying in a freestall on their preferred surface is as favorable as lying on their least preferred surface. However, the difference in lying time between the 2 least preferred options in stage $3(\mathrm{P} 1+$ freestall and P3 + open) was $\sim 1 \mathrm{~h}$. Differences of this magnitude were significant in the analysis of stage 1 and stage 2 $(\mathrm{n}=24)$ but may not have been detectable in stage 3 due to the smaller sample size $(\mathrm{n}=19)$. We observed no preference during stage 1 when freestalls were on the surfaces, with cows lying on average for a similar amount of time on both ST and M. However, Figure

\section{Cow Lying Preference for Stages 1, 2, and 3}

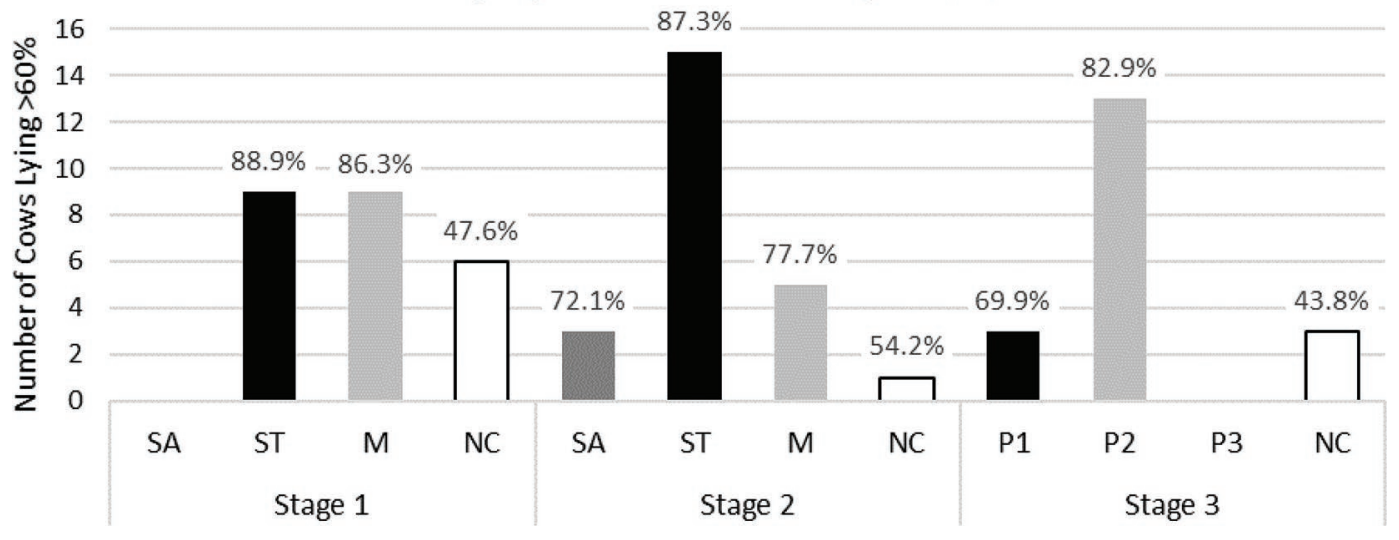

Figure 6. Number of cows that had a strong preference $(>60 \%$ total lying time) on each lying option $(\mathrm{SA}=\mathrm{sand} ; \mathrm{ST}=$ straw; $\mathrm{M}=\mathrm{mat}-$ tress; $\mathrm{P} 1=\mathrm{P} 1+$ freestall; $\mathrm{P} 2=\mathrm{P} 2+$ open; $\mathrm{P} 3=\mathrm{P} 3+$ open, where $\mathrm{P}=$ preference and numbers 1 to 3 indicate the order of preference for the 3 surfaces in stage 2) with the average percentage of total lying time for that lying option and number of cows with no clear choice for just one surface $(\mathrm{NC})$ with the average percentage of total lying time for the surface they lay on the most during stage 1 (freestalls; $\mathrm{n}=24$ ), stage 2 (open space; $\mathrm{n}=24$ ), and stage 3 (trade-off; $\mathrm{n}=19$ ). 
6 illustrates that this was due to some cows choosing to spend the majority of their lying time on ST and some on $\mathrm{M}$, rather than most cows splitting their time between both surfaces. During stage 2, the majority of cows had a strong preference for ST.

As predicted for the current study, these cows did choose to trade their preferred surface type for an open lying space. However, it has been suggested in other studies that cows are less focused on the spatial constraints of a freestall when deciding where to lie down, and more so on the freestall surface. Studies investigating the effect of aspects of the freestall structure, such as stall length, stall width, and neck rail placement, on lying time in cows (Tucker et al., 2004, 2005) tend to yield less definitive results than studies investigating the effect of stall surface on cow lying preference (Manninen et al., 2002; Tucker et al., 2003; Norring et al., 2010). This was further demonstrated in a study whereby cows chose to lie in freestalls over alternative freestalls with neck rails removed and stall dividers replaced with a wooden board protruding from the deep-sand bedding, alluding to an open space (Abade et al., 2015). However, the changes made to the total lying space in these studies assessing use of "adjusted" freestalls were relatively small compared with offering cows a true open lying area, as was done in the present study. Fregonesi et al. (2009) found that cows preferred an open lying area, of the same total lying area and same lying surface, over freestalls, showing the value of a true open lying space to cows, which is supported by the results in the current study.

Overall, in the current study, when cows had a choice, they generally preferred lying on surfaces other than sand, which could be due to the overall lack of previous experience on sand bedding compared with $\mathrm{M}$ and ST. When Manninen et al. (2002) gave 4 groups of cows, with no previous experience of sand, a free choice of sand, straw, and soft rubber mats in freestalls, the cows avoided the sand freestalls, sometimes even choosing to lie in the passageways to avoid them. In the Manninen et al. (2002) study, after the first 2 groups of cows had refused to use the sand freestalls, the second 2 groups were given a 3 -d forced period on each of the different beds before the choice period. These cows were found to use the sand freestalls more often, demonstrating the importance of resource exposure before preference tests. Similarly, Tucker et al. (2003) found that cows previously housed on deep-bedded sawdust freestalls had a preference for sawdust over freestalls with deepbedded sand or with rubber mattresses bedded with sawdust, but after a 2-d forced period on each surface, 2 out of the 12 cows switched their preference to sand. In Tucker et al. (2003), the rubber mattress freestalls were the least preferred and were the surface the cows had the least experience with before the study. It is worth noting that in the current study, when cows had no choice in lying surface (in the training period), there was no difference in total lying times between sand and the other surfaces, suggesting that although these cows did not have a preference for sand, it was not sufficiently aversive when they had no other lying option to cause animal welfare challenges associated with reduced lying times.

Cows lay down for $\sim 1 \mathrm{~h}$ longer during stage 2 , when freestalls were removed, compared with stage 1 , when freestalls were present, both when cows had no choice of surface (training periods) and a choice of surface (choice periods). Using time spent lying down as an indicator of comfort (Haley et al., 2000), this would suggest that cows find lying down in a freestall less comfortable than lying down in a more open space, even when given a choice of lying surface types. Although these results are significant, we must consider whether a difference of $\sim 1 \mathrm{~h}$ is biologically significant. Studies have shown that cows have a daily lying time ranging between 11.1 and $12.5 \mathrm{~h}$, depending on stage in lactation (Maselyne et al., 2017), and heifers have an inelastic demand to lie down for between 12 and $13 \mathrm{~h}$ (Jensen et al., 2005). Lying times reported for all stages of this study were greater than $13 \mathrm{~h}$, suggesting that lying comfort was not compromised in a freestall during this study.

In the current study, during the training periods, when there was no choice of lying surface, surface type had an effect on lying behavior, with cows on SA having the longest but least frequent lying bouts. However, the spatial constraints of a freestall did not affect lying behavior, with no difference in lying bout duration or frequency found between stage 1 (freestalls on) and stage 2 (no freestall). Longer but fewer lying bouts are generally reported on harder lying surfaces, with cows more reluctant to stand up and lie down on harder surfaces due to the discomfort experienced during the process (Herlin, 1997; Haley et al., 2000, 2001; Tucker et al., 2003). This would indicate that cows in this study found sand an uncomfortable surface on which to lie down on and from which to get back up, which is supported by cow avoidance of SA during the choice periods. Additionally, lying space did not affect this lying behavior, suggesting that the freestall does not impede the process of lying down and getting up for these cows. In contrast to these results, studies have reported that, compared with an open lying area (such as pasture or an open indoor lying area), cows do exhibit longer but fewer lying bouts when in a freestall (Haley et al., 2000; Hernandez-Mendo et al., 2007 ) and that the freestall is impeding the lying-down and getting-up motions. However, unlike the current 
study, those studies had a confounding factor of surface type, further suggesting that surface type can affect lying behavior, with lying bout duration and frequency being an indicator of lying comfort but only in terms of surface, not necessarily space.

An interaction was found between cow choice for lying surface and surface location within the pen during the stage 1 choice period. Because this interaction was only seen for stage 1 , it could be linked to the training protocol, whereby cows were always trained on the northeast surface when first introduced into the pen. Considering their general avoidance of SA, and possible avoidance of the first surface they were trained on when they entered the pens, when these options were removed (see Figure 4), the locations of $\mathrm{M}$ and ST were, for the majority, in the middle and southwest, respectively. Had the cows been given a couple of days to adjust to the pens before data collection began, this interaction may have been minimized.

Improved welfare aided simply by having control over one's environment, described as "agency" (Wemelsfelder, 1997; Špinka, 2019), has been proposed as a reference point for welfare enhancement (Mellor, 2015, 2016; Mellor and Beausoleil, 2015). It has been suggested that giving cows the ability to have choice within their environment, with even a perceived sense of control, may improve welfare (Motupalli et al., 2014; Webster, 2016; Charlton and Rutter, 2017). In the current study, cows lay down longer when given a choice of surfaces compared with during the training stages, when they only had access to one lying surface at a time. Similarly, Legrand et al. (2009) found that when given the choice of indoor freestalls and pasture, cows spent longer lying down than when they were confined to pasture alone. However, the difference in both studies was relatively small and highlights that the full extent of the effects of offering animals choice over their environment is unknown and requires further study.

\section{CONCLUSIONS}

On average, when a freestall was refitted onto the cow's preferred surface and these cows were presented with a trade-off between lying on their preferred surface or an open lying space of less preferred surface, the majority of these cows chose the open lying space. These cows made no choice between ST and M when a freestall were present; however, this was most likely due to some cows having a strong preference for ST and some for $\mathrm{M}$, rather than most cows splitting their time evenly between the 2 surfaces. When the freestall was removed, most cows had a strong preference for ST. These results suggest that when choosing where to lie down, these cows valued an open lying space, without a freestall, over their preferred surface type. More work is needed to investigate cow motivation for open lying space and the relationship between this and surface type.

\section{ACKNOWLEDGMENTS}

This study was funded by AHDB Dairy (Kenilworth, UK). The authors thank the technical and farm staff as well as the students at SRUC Dairy Research Centre, Crichton Royal Farm, particularly Ainsley Bagnall, John Dickinson, Isla McCubbin, Ailsa Thomson, Hugh McClymont, Darren Young, Jim Gordon, John Neil, Laura Hunter, and David Bell. The authors acknowledge and appreciate the assistance of Ian Nevison (Biomathematics and Statistics Scotland, Edinburgh, UK) with statistical analysis. The SRUC receives core funding from Rural and Environmental Science and Analytical Services, Scottish Government. The authors confirm that there were no conflicts of interest influencing this study.

\section{REFERENCES}

Abade, C. C., J. A. Fregonesi, M. A. G. von Keyserlingk, and D. M. Weary. 2015. Dairy cow preference and usage of an alternative freestall design. J. Dairy Sci. 98:960-965. https://doi.org/10.3168/ jds.2014-8527.

Charlton, G. L., and S. M. Rutter. 2017. The behaviour of housed dairy cattle with and without pasture access: A review. Appl. Anim. Behav. Sci. 192:2-9. https://doi.org/10.1016/j.applanim 2017.05.015.

Charlton, G. L., S. M. Rutter, M. East, and L. A. Sinclair. 2011. Effects of providing total mixed rations indoors and on pasture on the behavior of lactating dairy cattle and their preference to be indoors or on pasture. J. Dairy Sci. 94:3875-3884. https://doi.org/ 10.3168 /jds.2011-4172.

Charlton, G. L., S. M. Rutter, M. East, and L. A. Sinclair. 2013. The motivation of dairy cows for access to pasture. J. Dairy Sci. 96:4387-4396. https://doi.org/10.3168/jds.2012-6421.

Cooper, M. D., D. R. Arney, and C. J. C. Phillips. 2007. Two- or fourhour lying deprivation on the behavior of lactating dairy cows. J. Dairy Sci. 90:1149-1158.

Duncan, I. J. 1992. Measuring preferences and the strength of preferences. Poult. Sci. 71:658-663. https://doi.org/10.3382/ps.0710658.

Ferguson, J. D., D. T. Galligan, and N. Thomsen. 1994. Principal descriptors of body condition score in Holstein cows. J. Dairy Sci. 77:2695-2703. https://doi.org/10.3168/jds.S0022-0302(94)77212 $-\mathrm{X}$.

Flower, F. C., and D. M. Weary. 2006. Effect of hoof pathologies on subjective assessments of dairy cow gait. J. Dairy Sci. 89:139-146. https://doi.org/10.3168/jds.S0022-0302(06)72077-X.

Fraser, A. F. 1983. The behaviour of maintenance and the intensive husbandry of cattle, sheep and pigs. Agric. Ecosyst. Environ. 9:123. https://doi.org/10.1016/0167-8809(83)90002-6.

Fregonesi, J. A., M. A. G. von Keyserlingk, C. A. Tucker, D. M. Veira, and D. M. Weary. 2009. Cow preference and usage of free stalls compared with an open pack area. J. Dairy Sci. 92:5497-5502.

Haley, D. B., A. M. de Passillé, and J. Rushen. 2001. Assessing cow comfort: Effects of two floor types and two tie stall designs on the behaviour of lactating dairy cows. Appl. Anim. Behav. Sci. 71:105-117. https://doi.org/10.1016/S0168-1591(00)00175-1.

Haley, D. B., J. Rushen, and A. M. de Passillé. 2000. Behavioural indicators of cow comfort: Activity and resting behaviour of dairy 
cows in two types of housing. Can. J. Anim. Sci. 80:257-263. https: //doi.org/10.4141/A99-084.

Haskell, M. J., L. J. Rennie, V. A. Bowell, M. J. Bell, and A. B. Lawrence. 2006. Housing system, milk production, and zero-grazing effects on lameness and leg injury in dairy cows. J. Dairy Sci. 89:4259-4266. https://doi.org/10.3168/jds.S0022-0302(06)72472 -9 .

Herlin, A. H. 1997. Comparison of lying area surfaces for dairy cows by preference, hygiene and lying down behaviour. Swed. J. Agric. Res. 27:189-196.

Hernandez-Mendo, O., M. A. G. von Keyserlingk, D. M. Veira, and D. M. Weary. 2007. Effects of pasture on lameness in dairy cows. J. Dairy Sci. 90:1209-1214. https://doi.org/10.3168/jds.S0022 -0302(07)71608-9.

Jensen, M. B., L. J. Pedersen, and L. Munksgaard. 2005. The effect of reward duration on demand functions for rest in dairy heifers and lying requirements as measured by demand functions. Appl. Anim. Behav. Sci. 90:207-217. https://doi.org/10.1016/j.applanim 2004.08.006

Kilgour, R. J. 2012. In pursuit of "normal": A review of the behaviour of cattle at pasture. Appl. Anim. Behav. Sci. 138:1-11. https://doi .org/10.1016/j.applanim.2011.12.002.

Legrand, A. L., M. A. G. von Keyserlingk, and D. M. Weary. 2009. Preference and usage of pasture versus free-stall housing by lactating dairy cattle. J. Dairy Sci. 92:3651-3658. https://doi.org/10 $.3168 /$ jds.2008-1733.

Manninen, E., A. M. de Passillé, J. Rushen, M. Norring, and H. Saloniemi. 2002. Preferences of dairy cows kept in unheated buildings for different kind of cubicle flooring. Appl. Anim. Behav. Sci. 75:281-292. https://doi.org/10.1016/S0168-1591(01)00206-4.

March, M. D., M. J. Haskell, M. G. G. Chagunda, F. M. Langford, and D. J. Roberts. 2014. Current trends in British dairy management regimens. J. Dairy Sci. 97:7985-7994. https://doi.org/10.3168/jds 2014-8265.

Margerison, J. 2011. Dairy cattle. Pages 68-119 in Management and Welfare of Farm Animals. 5th Edition. J. Webster, ed. WileyBlackwell, Chichester, UK.

Maselyne, J., M. Pastell, P. T. Thomsen, V. M. Thorup, L. Hänninen, J. van Geyte, A. vanNuffel, and L. Munksgaard. 2017. Daily lying time, motion index and step frequency in dairy cows change throughout lactation. Res. Vet. Sci. 110:1-3. https://doi.org/10 .1016/j.rvsc.2016.10.003.

Mellor, D. J. 2015. Enhancing animal welfare by creating opportunities for positive affective engagement. N. Z. Vet. J. 63:3-8. https://doi .org/10.1080/00480169.2014.926799.

Mellor, D. J. 2016. Updating animal welfare thinking: Moving beyond the "Five Freedoms" towards "A Life Worth Living". Animals (Basel) 6:21. https://doi.org/10.3390/ani6030021.

Mellor, D. J., and N. J. Beausoleil. 2015. Extending the 'Five Domains' model for animal welfare assessment to incorporate positive welfare states. Anim. Welf. 24:241-253. https://doi.org/10.7120/ 09627286.24.3.241.

Metz, J. H. M. 1985. The reaction of cows to a short-term deprivation of lying. Appl. Anim. Behav. Sci. 13:301-307. https://doi.org/10 .1016/0168-1591(85)90010-3.

Motupalli, P. R., L. A. Sinclair, G. L. Charlton, E. C. Bleach, and S. M. Rutter. 2014. Preference and behavior of lactating dairy cows given free access to pasture at two herbage masses and two distances. J. Anim. Sci. 92:5175-5184. https://doi.org/10.2527/jas .2014-8046.

Munksgaard, L., M. B. Jensen, L. J. Pedersen, S. W. Hansen, and L. Matthews. 2005. Quantifying behavioural priorities - effects of time constraints on behaviour of dairy cows, Bos taurus. Appl Anim. Behav. Sci. 92:3-14. https://doi.org/10.1016/j.applanim .2004.11.005.

Norring, M., E. Manninen, A. M. de Passillé, J. Rushen, and H. Saloniemi. 2010. Preferences of dairy cows for three stall surface materials with small amounts of bedding. J. Dairy Sci. 93:70-74. https://doi.org/10.3168/jds.2009-2164.

Smid, A. M. C., E. E. A. Burgers, D. M. Weary, E. A. M. Bokkers, and M. A. G. von Keyserlingk. 2019. Dairy cow preference for access to an outdoor pack in summer and winter. J. Dairy Sci. 102:1551-1558. https://doi.org/10.3168/jds.2018-15007.

Špinka, M. 2019. Animal agency, animal awareness and animal welfare. Anim. Welf. 28:11-20. https://doi.org/10.7120/09627286.28.1.011.

Tucker, C. B., L. Munksgaard, E. M. Mintline, and M. B. Jensen. 2018. Use of a pneumatic push gate to measure dairy cattle motivation to lie down in a deep-bedded area. Appl. Anim. Behav. Sci. 201:15-24. https://doi.org/10.1016/j.applanim.2017.12.018.

Tucker, C. B., D. M. Weary, and D. Fraser. 2003. Effects of three types of free-stall surfaces on preferences and stall usage by dairy cows. J. Dairy Sci. 86:521-529. https://doi.org/10.3168/jds.S0022 -0302(03)73630-3.

Tucker, C. B., D. M. Weary, and D. Fraser. 2004. Free-stall dimensions: Effects on preference and stall usage. J. Dairy Sci. 87:12081216. https://doi.org/10.3168/jds.S0022-0302(04)73271-3.

Tucker, C. B., D. M. Weary, and D. Fraser. 2005. Influence of neckrail placement on free-stall preference, use, and cleanliness. J. Dairy Sci. 88:2730-2737. https://doi.org/10.3168/jds.S0022 -0302(05)72952-0.

USDA. 2016. Dairy 2014: Dairy Cattle Management Practices in the United States, 2014. Accessed May 22, 2020. https://www .aphis.usda.gov/animal_health/nahms/dairy/downloads/dairy14/ Dairy14_dr_PartI_1.pdf.

van den Pol-van Dasselaar, A., T. V. Vellinga, A. Johansen, and E. Kennedy. 2008. To graze or not to graze, that's the question. Grassl. Sci. Eur. 13:706-716.

Webster, J. 2016. Animal welfare: Freedoms, dominions and "A life worth living". Animals (Basel) 6:35. https://doi.org/10.3390/ ani6060035.

Wemelsfelder, F. 1997. The scientific validity of subjective concepts in models of animal welfare. Appl. Anim. Behav. Sci. 53:75-88. https: //doi.org/10.1016/S0168-1591(96)01152-5.

\section{ORCIDS}

L. Shewbridge Carter @ https://orcid.org/0000-0003-0773-3074

S. M. Rutter ® https://orcid.org/0000-0002-9259-6061

D. Ball $\odot$ https://orcid.org/0000-0003-3098-1025

J. Gibbons @ https://orcid.org/0000-0001-7719-1587

M. J. Haskell ๑ https://orcid.org/0000-0001-9373-0624 